\title{
The role of selected postsynaptic scaffolding proteins at glutamatergic synapses in autism-related animal models
}

\author{
Veronika Meliskova $^{1,2}$, Tomas Havranek ${ }^{1,3}$, Zuzana Bacova ${ }^{1}$, Jan Bakos ${ }^{1,2, *}$ \\ ${ }^{1}$ Institute of Experimental Endocrinology, Biomedical Research Center, Slovak Academy of Sciences, 84505 Bratislava, Slovakia \\ ${ }^{2}$ Institute of Physiology, Faculty of Medicine, Comenius University in Bratislava, 81106 Bratislava, Slovakia \\ ${ }^{3}$ Institute of Anatomy, Faculty of Medicine, Comenius University in Bratislava, 81106 Bratislava, Slovakia \\ ”Correspondence: j.bakos@savba.sk (Jan Bakos)
}

DOI:10.31083/j.jin2004106

This is an open access article under the CC BY 4.0 license (https://creativecommons.org/licenses/by/4.0/).

Submitted: 20 May 2021 Revised: 9 July 2021 Accepted: 18 August 2021 Published: 30 December 2021

Pathological changes in synapse formation, plasticity and development are caused by altered trafficking and assembly of postsynaptic scaffolding proteins at sites of glutamatergic and gammaaminobutyric acid synapses, suggesting their involvement in the etiology of neurodevelopmental disorders, including autism. Several autism-related mouse models have been developed in recent years for studying molecular, cellular and behavioural defects to understand the etiology of autism and test potential treatment strategies. In this review, the role of alterations in selected postsynaptic scaffolding proteins in relevant transgene autism-like mouse models is explained. A summary is also provided of selected animal models by paying special attention to interactions between guanylate kinases or membrane-associated guanylate kinases, as well as other synapse protein components which form functional synaptic networks. The study of early developmental stages of autism-relevant animal models help in the understanding the origin and development of diverse autistic symptomatology.

Keywords

Scaffolding proteins; $\mathrm{SH}_{3}$ domain and ankyrin repeat containing proteins (SHANKs); HOMER1; Fragile $X$ mental retardation protein (FMRP); Contactinassociated protein-like 2 (CNTNAP2); Autism

\section{Introduction}

To understand the etiology of neurodevelopmental disorders, it is necessary to systematically examine the structural consequences of synaptic remodeling. The relevant players involved in cytoskeletal remodeling and synaptic plasticity include various actin-binding proteins, microtubulebinding proteins and cell-adhesion molecules [1]. To date, a wide panel of Shank mutant mouse models has been developed with characteristic features that are collectively called "shankopathies" [2, 3]. For instance, abnormal patterns of cell-adhesion molecules and scaffolding proteins, in association with altered neuronal morphology, have been observed in the "SH3 domain and ankyrin repeat containing protein 3" (Shank3) deficient mouse model [4]. Moreover, it has recently been demonstrated that altered expression of specific genes are involved in processes of neurite elongation and synapse formation in the early developmental periods of MAGE Family Member L2 (Magel2)-deficient mice [5], which is another model known for the presence of autismlike symptoms. Currently, it appears that crucial factors that play a role in the pathogenesis of autism are defects and abnormalities found in postsynaptic density proteins [6-8]. Alterations for a wide range of postsynaptic density molecules and scaffolding proteins are currently being investigated at the molecular and cellular level in the context of neurodevelopmental disorders, with membrane-associated guanylate kinases representing the largest group amongst them [9]. Several lines of evidence have suggested that pathological changes in synapse formation, plasticity and development are caused by altered trafficking and assembly of postsynaptic scaffolding proteins at glutamatergic and gammaaminobutyric acid-(GABA)ergic-synapses, thereby suggesting their involvement in the etiology of neurodevelopmental disorders $[10,11]$.

Scaffolding proteins link several membrane proteins and ion channels with a dynamic network of cytoskeletal proteins. The specific interactions among protein complexes are associated with activation of diverse signaling pathways in subtypes of neuronal cells. In particular, there are known differences in the composition of postsynaptic sites at glutamatergic and GABAergic neurons in cortical and subcortical areas of the brain [12-14]. Structural scaffolding proteins allow for the recruitment of large, functional complexes that serve to modulate signaling pathways in both glutamatergic and GABAergic neurons. Moreover, processes such as receptor stabilization, subcellular localization and trafficking are determined by the functional interactions of scaffolding proteins. Structural and functional changes of these proteins are associated with the pathologies observed in neurodevelopmental disorders at numerous cellular and subcellular levels [1]. One group of scaffolding molecules includes SHANK proteins, which represent a large and multidomain family. Shank genes are important candidates for the modelling of autism spectrum disorders in mice. In this context, a variety of genetic models have been generated within the last 
few years, among them Shank1-3-deficient mice. Additionally, Contactin-associated protein-like 2 (CNTNAP2), an organising and adhesive molecule known for its role in axons, dendrites and synaptic connections, is also widely-replicated as an autism-predisposition gene [15]. Genetic variation in Cntnap2 is considered an important variable in synaptic phenotypes and associated with both excitatory and inhibitory synaptic abnormalities $[16,17]$. It is very likely that excitatory and inhibitory synaptic changes could specifically manifest, depending on alterations in scaffolding proteins and thus result in heterogeneous autistic behavioural phenotypes.

For the purpose of this review, scaffolding proteins and their associated molecules were selected, whose variability is likely to be casually-linked with the etiology of autism spectrum disorders. The role of synaptic components in excitatory/inhibitory balance in the brain in relation to autism is also discussed. The role of major postsynaptic density proteins that are typically present in the excitatory synapses in relevant transgene autism-like mouse models are described. The animal models chosen are useful for understanding the normal and altered function of postsynaptic scaffolding proteins at excitatory synapses. The involvement of membraneassociated guanylate kinases in regulating synaptic vesicle proteins in autism-related conditions is also particularly explained. Due to the great complexity of synaptic composition, this review is limited to clarifying the links between excitatory glutamate receptors and postsynaptic density proteins, which are most relevant for the pathological processes found in autism.

\section{Postsynaptic density (PSD) and scaffolding proteins}

The postsynaptic density (PSD) is typically defined by the presence of numerous scaffolding proteins, receptors and signaling molecules that are in close proximity to the postsynaptic membrane [18]. Since they are important components of the PSD, scaffolding proteins play a crucial role in synaptic plasticity mediated by anchoring and clustering of glutamate receptors and interactions with cell-adhesion molecules $[19,20]$. Additionally, they are involved in connections between postsynaptic receptors and downstream signaling molecules and also adjust the cytoskeletal dynamics [21]. Various groups of scaffolding proteins occur in different layers of the PSD. The spatial distribution and localization of individual proteins can be adjusted by neuronal activity, which may lead to changes in their post-translational modifications, as well as changes in their binding partners. The groups of scaffolding proteins differ from one another in their modular domain compositions, distinct interaction and binding complexes.

\subsection{Membrane-associated guanylate kinases at postsynaptic density}

Membrane-associated guanylate kinases (MAGUKs) comprise one of the largest groups of scaffolding proteins at the postsynaptic density. MAGUKs have a critical role in the physiology and development of several tissues of metazoan organisms [22]. The family of MAGUKs includes a guanylate kinase-like domain, which contains members such as PSD-93, PSD-95, as well as the synapse-associated proteins SAP-97 and SAP-102. In humans, the SAP-97 and SAP-102 proteins are known to be encoded by genes, "discs large homolog" DLG1 and DLG3. MAGUKs contribute to maintaining excitatory and inhibitory synaptic inputs in the brain by regulating the formation of excitatory glutamatergic synapses. Therefore, MAGUKs are involved in processes of synaptic plasticity by regulating the localization and compartmentalization of glutamate receptors [23]. In the PSD architecture of excitatory synapses, MAGUKs-mainly PSD-95, participate in the organization of ionotropic glutamate receptors and associated signaling proteins, which adjust the synaptic strength. Diverse adaptations of MAGUK proteins in glutamatergic synapses, such as altering interactions between MAGUKs and ionotropic glutamate receptor subunits, often occur in neurodevelopmental disorders [24]. For instance, a mutation in the gene for the glutamate receptor subunit GRIN2B has been found in a patient with autism [25]. These authors explain that impaired GluN2B subunit binding to MAGUK proteins is associated with decreased dendritic spine density. Furthermore, it has recently been widely discussed that developmental clustering and coupling of $N$-methyl- ${ }^{-}$-Aspartate (NMDA) receptor subunits could be affected by MAGUK family proteins [9]. One recent study has suggested that a deficiency in a member of MAGUK family of proteins PSD-95 affects GABAergic inhibitory synapses. The authors of that study explain their results by a PSD-95 deficiency that enhances the inhibitory synapse activity by enhancing transport mechanisms of inhibitory cell adhesion molecules [26]. The relationship between MAGUKs and excitatory/inhibitory balance in the brain is therefore quite complex and depends upon the interactions and trafficking of cytoskeletal components from excitatory to inhibitory synapses.

\subsection{SHANK proteins at postsynaptic density}

Another large protein family at the postsynaptic density includes SHANK proteins. They are characterized as multidomain scaffolding proteins, which are associated with neurotransmitter receptors, signaling molecules and actin filaments. In conjunction with their binding partners, SHANK and guanylate kinase-associated proteins (GKAP) contribute to the organization of glutamate receptors in the PSD [27]. Based on their interactions with proteins, they recruit molecular machineries for G-protein-mediated signaling, leading to the control of calcium homeostasis in dendritic processes of neurons. They also participate in morphological changes which lead to the maturation of dendritic spines and synapse remodeling [28]. The proteins of the SHANK family are encoded by the three related SHANK genes: 1, 2 and 3. SHANK family proteins are mostly developed in excitatory glutamatergic synapses in mammalian brains $[29,30]$. Although they share high, structural similarity and preva- 
lently localize to the postsynaptic terminal, SHANK proteins are differentially-expressed during brain development, with SHANK2 and SHANK3 finalizing before SHANK1. SHANK2 and SHANK3 are therefore considered critical for several aspects of neuroplasticity during development [31]. Studies have demonstrated that SHANK1 protein levels increase from birth through early development, followed by a slight decrease in adulthood in the cerebellum and cortex [32]. In fact, SHANK1-3 protein components represent critical determinants of excitatory synaptic function. Therefore, whenever balanced expression of the different SHANK proteins is disturbed or diverse alterations in Shank isoforms occur, these events result in various dysfunctions of synaptic transmission (as described below in section 3.5).

SHANK full-length proteins contain ankyrin repeat domains, a SH3 domain, a single PDZ domain, a Proline-rich region (PRD) and a Sterile alpha motif domain (SAM). The PDZ SHANK domain interacts with the "SAPAP" (Synapseassociated protein (SAP) 90/Postsynaptic density (PSD)-95associated protein) family. The PRD binds to HOMER and Cortactin and this interaction is important for cytoskeletal regulation, as well as for modification of synaptic transmission [33]. SHANK3 is highly enriched in corticostriatal glutamatergic synapses [34], which are a part of neural circuits that are thought to be dysfunctional in ASD. High Shank1 gene expression levels occur in cortical and subcortical brain regions, including the amygdala and hippocampus, while Shank2 gene expression is enriched in cortical areas and the thalamus [34]. In the corticostriatal projections, activity from different areas of the cerebral cortex converges into the striatum and the output is then returned to the cortical layers through thalamic pathways, serving as an aid in motor decisions and behaviour. Therefore, different synaptic errors in different parts of the circuit will ultimately affect cortical activity-this could also be a convergence mechanism for recurrent behaviour with distinct genetic causes particularly in some disorders [35]. Functional deficits of a single copy of SHANK3 are one of the major causes of ASD, Phelan-McDermid syndrome (PMS) and mental disability [6].

\subsection{HOMER protein homolog at postsynaptic density}

The HOMER protein homolog represents an important postsynaptic density scaffolding element, which is involved in various processes of synaptic plasticity, including changes in intracellular calcium. To date, three gene families have been characterized-HOMER 1, 2 and 3 with both long and short-form variants. Long forms of HOMER proteins are a part of the PSD and are consecutively expressed, unlike the short forms, which are known as cytosolic molecules with low expression under basal conditions [36]. Alternative splicing of HOMER into long and short forms has been investigated in the context of the postsynaptic polymeric network structure. For instance, stoichiometric structures connecting HOMER, SHANK and MAGUK proteins have previously been suggested [37]. Indeed, one recent study found that the glutamatergic synapse protein interaction network includes interactions between HOMER and SHANK proteins [38]. The balance between long and short forms of HOMER contributes to normal synapse functioning; therefore, it is assumed that alterations in HOMER expression, folding, and binding to other scaffolding proteins could be associated with the pathological processes found in autism. Multiple controversies are associated with the functional consequences of mutations in HOMER proteins, particularly in the context of autism spectrum disorders and are currently being discussed [39]. HOMER proteins are responsible for the links between metabotropic glutamate receptors and PSD proteins [40], so disruption of the group-I metabotropic glutamate ( $\mathrm{mGlu}$ ) receptor mediated signaling can contribute to the etiology of autism [41].

\subsection{Calmodulin-dependent protein kinase II-alpha at postsynaptic density}

The calmodulin-dependent protein kinase II-alpha $(\mathrm{CaMKII} \alpha)$ is a well-defined and abundant protein in the PSD and participates in the control of signal modality in synaptic connections. Activity of CaMKII $\alpha$ has previously been demonstrated as an important factor in the phosphorylation of synaptic Ras GTPase-activating proteins (synGAP -expressed in the postsynaptic density), distribution of synGAP from postsynaptic sites and for the activation of postsynaptic Ras-proximate-1 or Ras-related protein 1 (Rap1). SynGAP represents a neuron-specific Ras and Rap GTPase-activating protein (GAP) found in large amounts in PSD fraction [42]. Additionally, CaMKII $\alpha$ plays an essential role in the regulation of memory and learning processes, as well as an activity-dependent role in spine density limitation during postnatal development $[42,43]$. One recent study found that CaMKII $\alpha$ is recruited to the scaffolding protein SHANK3 sub-compartment of the PSD [44]. Moreover, the binding of SHANK3 to CaMKII $\alpha$ potentially modulates dendritic spine morphology [45]. This complicated concept could be useful for explanation of the role of CaMKII $\alpha$ in the abnormal neuronal morphology observed in autism [1, 46]. In fact, mutation in CaMKII $\alpha$ contributes to alterations in dendritic morphology as well as synaptic transmission and thus consequently leads to ASD-related behavioural phenotypes [8].

\section{Autism-related mouse models}

Mouse experimental models provide an option for studying autism spectrum disorder (ASD) at cellular, molecular, neuronal circuit and behavioural levels, offering possibilities in which behavioural abnormalities and their compensation by potential drug compounds can be screened before translation to humans. The main advantages of mouse models of ASD are that they are genetically flexible and practical. Additionally, various ASD models that present basic phenotypes are commercially available and ready to use in current research. However, mouse models have their own limitations, as certain behavioural phenotypes in neuropsychiatric disorders cannot be evaluated in mice. For instance, the com- 
munication problems and language development delay often present in autistic children can only be poorly addressed by the study of ultrasonic calls $[47,48]$. Moreover, some of them are obstructed in mouse models based on noticeable behaviours. A further risk is that the evaluation of the underlying phenotypes of ASD may be confounded with familiar comorbidities, including locomotor dysfunction, sensory dysfunction, learning loss and anxiety [49]. There are several types of genes in which deficiency plays a significant role in the pathophysiology of neurodevelopmental diseases with autism symptoms. The limitations of mouse models also include the fact that in humans most of the patients with ASDrelated genetic variants are heterozygous, while in experimental conditions homozygous mice are usually investigated. Therefore, allele-specific gene expression differences in humans and experimental models should also be taken into account. The interpretation of data coming from experimental models should be carefully considered, as the concept of diverse consequences of different versions of the genes adds another component to the variability of behavioral phenotypic spectrum in ASD patients. Even more complicated, some consequences appear during specific stages in development in a brain region dependent manner.

\subsection{T-box brain transcription factor 1}

The T-Box Brain Transcription Factor 1 (Tbr1) represents a gene that encodes a transcription factor with distinct prenatal and postnatal molecular actions. This gene has a high probability of alterations in ASD [50]. Neuronspecific Tbr1 adjusts the regional and laminar character of cerebral cortex regions in the developing brain [51]. Numerous studies have previously found that Tbr1 regulates the identity of neocortical regions in the regional and laminar pathways of the developing brain [51-54]. The Calcium/Calmodulin Dependent Serine Protein Kinase (Cask) gene codes the MAGUK protein, wherein the $\mathrm{N}$-terminal half consists of a calcium/calmodulin independent kinase (CaMK) domain and two LIN-2,7 (L27) domains, as well as the C-terminus half, which consists of the PDZ domain, Src homology 3 (SH3) and the guanylate kinase (GuK) domain [55]. Wang et al. [56] evidenced that overexpression of Tbr1 and Cask increased promoter activities of some of these genes, including the NMDA receptor $2 \mathrm{~b}(\mathrm{Nr} 2 b)$, glycine transporter and interleukin 7 receptor $(I L 7 R)$. It was shown that expression of $N r 2 b$ was consistently downregulated in $T b r-1$ deficient mice. The TBR-1/CASK protein complex is involved in downstream control of the expression of the mentioned genes, thereby modulating brain function. The expression of Tbr1 is upregulated by neuronal activation together with the synaptic PDZ protein CASK and the nucleosome assembly protein CINAP (CASK-interacting nucleosome assembly protein), which forms a complex participating in the control of the glutamatergic receptor subunits [46]. Deriziotis et al. [57] and Sakai et al. [58] investigated direct interaction between TBR1 and Forkhead Box P2 (FOXP2), which is a transcription factor known for its role in brain develop- ment. TBR1 was identified as a binding partner for CASK since it requires a C-terminal region. This interaction results in an increase of transcriptional activity of Tbr 1 by engagement of the nucleosome assembly protein CINAP (CASK interacting nucleosome assembly protein, also known as testis specific protein Y-encoded like 2, TSPYL2) into a promotor region containing the DNA binding motif for the T-box [59]. Numerous rodent studies have shown that the neurodevelopmental phenotypes associated with the mutation in PDZ protein CASK led to loss-of-function. Heterozygous mice display postnatal progressive microcephaly, hypoplasia of the optic nerves and cerebellum, growth retardation, as well as scoliosis [55, 60, 61]. Mutations in Tbr1 are accompanied by synaptic, neuronal, and behavioural dysfunctions associated with ASD. Tbr1 $1^{+/ K 228 E}$ mice displayed increased self-grooming, altered social interaction and increased anxiety-like behaviours [49]. Tbr1-deficient mice develop axonal (presynaptic) defects and other deficiencies in neuron morphology, such as immature dendritic spines and reduced synaptic density [48]. Moreover, it has been found that $\mathrm{Tbr} 1^{-/-}$mice suffer from several other postnatal abnormalities in lamination of the cerebral cortex. In heterozygous animals, the reduction of functional amygdala interconnections has been demonstrated along with autistic-like behaviours [62]. Huang et al. [63] demonstrated that $\mathrm{Tbr} \mathrm{I}^{+/-}$ mice manifested less-developed anterior commissures and also olfactory bulbs, a reduced population of interneurons and an atypical morphology of dendrites in olfactory mitral cells. The olfactory sense was not disturbed; however, Tbr1 haploinsufficiency affected olfactory discrimination. Characterization of cellular functions of Tbr1 with the use of mouse models is essential for understanding abnormalities in cortical lamination and in a broader context, it contributes to the deciphering of the complicated origin of neurodevelopmental disorders, including autism.

\subsection{Fmr1 gene}

The fragile $\mathrm{X}$ mental retardation 1 ( Fmr1) gene is located on the $\mathrm{X}$ chromosome and the expansion of trinucleotide CGG leads to its silencing with a consequent absence of the encoded fragile X mental retardation protein (FMRP), which is a synaptic RNA binding protein that modulates the duration of the action potential, as well as synaptic plasticity. These consequences result in a disease known as Fragile $\mathrm{X}$ syndrome (FXS) [64]. It has been demonstrated that neuroplasticity disorders belong to the main findings in animal models of FXS and that the lack of balance in inhibitory and excitatory neuronal circuits is the basis of many clinical manifestations of this disorder [65]. Fmr1 gene knockout mice have shown many deformities in neuronal plasticity and learning. Recent studies have suggested that dendritic spines are reduced in juvenile Fmr1 knock-out mice; however, the differences are not noticeable in adult mice [66, 67]. Sitzman et al. [64] demonstrated that Fmr1 deficient mice display deficits in synaptic plasticity and neurite extension. Several studies have also shown metabolic 
changes, namely that Fmr1 knockout mice have an increased rate of glucose metabolism, exalted oxidative and metabolic stress and deformities in their nitric metabolism of oxygen [64, 68, 69]. Todd et al. [70] demonstrated that FMRP levels are rapidly up-regulated in primary cortical neurons in response to the activation of the type I metabotropic glutamate receptor (mGluR1 and mGlur5) by agonist S-3,5dihydrophenylglycine. Further, that mRNA for PSD-95 is a scaffolding protein involved in synaptic plasticity, which contains a highly conserved canonical FMRP binding site within its 3' UTR. Furthermore, PSD-95 translates rapidly in response to the activation of glutamate receptors, since mGluR5 changes in PSD-95 expression are lost in neurons derived from FMRP deficient mice [71]. They hypothesize that FMRP is required for mGluR1 and mGluR5-dependent translation of PSD-95 and provide insight into the pathophysiology of FXS. DeMarco et al. [72] have suggested that FMRP regulates PSD-95 translation via activation of miR$N A s$, thus working together to mediate the reversible inhibition of the PSD-95 expression in neurons. In addition to alterations in excitatory glutamatergic neurotransmission, recent studies have suggested that $F m r 1$ knockout mice also suffer from abnormalities in inhibitory GABAergic neurotransmission [73]. Sabanov et al. [73] found that a significantlyreduced amplitude of evoked inhibitory postsynaptic currents decreased expression levels of GABA receptor subunits. Overall, most of the above-mentioned studies support the integrated view of the FMRP role in synaptic plasticity and postsynaptic structural remodeling. It is also clear that mutations or modifications of FMRP play an important role in developmental delays and the etiology of ASD. With the exception of PSD-95, it remains to be elucidated how FMRP might target other postsynaptic density proteins and affect synaptic remodeling.

\subsection{Contactin-associated protein-like 2 (CNTNAP2)}

Contactin-associated protein-like 2 (CNTNAP2) is a transmembrane cell-adhesion molecule type I which occurs in the central and peripheral nervous system. It is highly expressed throughout the spinal cord and brain, especially in the frontal and temporal lobes, dorsal thalamus, striatum and specific cortical layers [74]. It is a member of the neuronexin family and has an essential role in neural development, belonging to one of the most susceptible genes for autism spectrum disorders [17]. Cntnap2 deficient mice are characterized by social deficits and repetitive seizures, and behaviours. Vogt et al. [75] assessed the CNTNAP2 function in mouse development and infection of cortical interneurons, utilizing a Cntnap2 null mouse. Lazaro et al. [76] found a significant decrease in excitatory and inhibitory synaptic inputs on pyramidal neurons of the prefrontal cortex of Cntnap2 knock-out mice. This means that reduced synaptic inputs can gain temporal coordination of neuronal firing in cortical collections. Scott et al. [77] report loss of CNTNAP2 in the rat causes autism-related alterations in social interactions, stereotypic behaviour and sensory processing.
Cntnap2 $2^{-/}$rats lack sociability and social behaviour. Other findings include alterations in sensory processing, increased avoidance to sounds of moderate intensity, deficit of rapid audiovisual temporal recalibration and exaggerated acoustic startle responses. Gao et al. [78] characterized an interaction between CNTNAP2 and the Partitioning-defective 3 protein (PAR3). These authors demonstrated that the two proteins interact through PDZ-mediated binding, since $\mathrm{CNTNAP2}^{+} / \mathrm{PAR}{ }^{+}$complexes are largely associated with clathrin-coated endocyte vesicles in heterologous cells. Overexpression of Par3, however, not a knockout lacking all PDZ domains, can cluster endogenous CNTNAP2 in primary neurons. Altogether, the aforementioned studies suggest a strong association of CNTNAP2 alterations in excitatory glutamatergic neurons with autism-related behavioural phenotypes. Although the mechanisms associated with how CNTNAP2 regulates glutamatergic synapses are not fully understood, it has been suggested that CNTNAP2 plays a role in the AMPA receptor subunit's trafficking [79]. Moreover, Cntnap2 knockdown decreased the number of functional excitatory synapses and the consequences observed in altered social behaviour were compensated by enhancement of the AMPA receptor function [80]. Taken together, CNTNAP2 is clearly a part of the molecular architecture of the postsynaptic density, which may be pathologically modified in autism and other neuropsychiatric disorders.

\subsection{Magel2 gene}

The MAGEL2 protein occurs at high levels in the hypothalamus and plays a crucial role in the regulation of subcellular processes that contribute to the recycling of membrane proteins from endosomes [81]. Protein truncation mutations in MAGEL2 result in Schaaf-Yang syndrome and MAGEL2 comes from a small array of genes deleted in PraderWilli syndrome. Abnormal daytime sleepiness and nocturnal and/or early morning awakening occur in people with Schaaf-Yang syndrome and Prader-Willi syndrome, while mice bearing a deletion of the Magel2 gene suffer from disrupted circadian rhythms [82]. Although Prader-Willi syndrome is a multigene neurodevelopmental disorder with various physiological and behavioural deficits, the clinical characteristics include severe hypotonia, a newborn's poor feeding due to reduced suckling reflexes, childhood-onset obesity, lower cognitive functioning and autistic symptoms [83]. Magel2-deficient mice manifest altered gene and protein expression of PSD-95 in early brain developmental stages [5]. Magel2-deficient mice have shown altered levels of oxytocin in the hypothalamus, as well as $50 \%$ neonatal mortality due to suckling problems [84]. Male mice who survive were shown to have deficits in the exploration of novel objects, social novelty and dimensional learning [84, 85].

\subsection{Shank family of genes}

Numerous Shank-deficient mouse models (with a deleted gene belonging to the Shank family) have been generated to provide clarification of the role of Shank proteins in vivo. 
By comparing individual Shank members, deletion of Shank1 proved to have milder phenotypic deficits than Shank2 and Shank3. Shank2 and Shank3 genes are more structurally similar compared to Shank1 [86]. Here, it needs to be emphasized that marked differences in alterations in behaviour and synaptic function of Shank deficient mice can be explained by remaining Shank isoforms $[87,88]$. Moreover, endophenotypes within ASD patients with different types of mutations likely depend on isoform-specific disruption of SHANKs [2].

Shank1 mRNA and proteins are found almost exclusively in the central nervous system when compared to Shank2 and Shank3 in rodents, which are expressed in many tissues, such as the kidney, brain, heart, spleen and liver [34]. Overexpression of Shank1 alters spine morphology [89]. The first mouse Shank model was created by Hung et al. [90] via disruption of the Shank1 gene through deletion of exons 14 and 15 , which leads to complete knockout of all Shank1 isoforms. Many studies have provided evidence of an ASD-related phenotype, which is defined by deficits of social communication, modifications in repetitive behaviour and deterioration in cognitive function. Behavioural phenotypes of Shank-mouse models depend on specific gene mutations and modifications, resulting in intellectual disability, schizophrenia and autism symptoms [91]. Shank1 deficient mice are characterized by lower psychomotor activation and higher levels of anxiety. Additionally, they have impaired contextual fear memory and improved acquisition [90, 92]. A study by Mao et al. [93] showed that Shank1 is highly present in Parvalbuminexpressing $(\mathrm{PV}+)$ fast-spiking inhibitory interneurons in the hippocampus. It was shown that a lack of Shank1 in these neurons leads to devaluation of afferent excitatory synaptic activity and inhibitory efferent synaptic activity to pyramidal neurons. The hippocampal CA1 pyramidal neurons in Shank1 deficient mice display a change in the excitatory/inhibitory balance, which can be considered a pathophysiologic feature of ASD. Dysregulation of excitatory/inhibitory balance in the hippocampus was displayed by lower expression of gephyrin (a scaffolding component of inhibitory synapses). Mossa et al. [86] investigated how simultaneous deletion of Shank1 and Shank3 affects brain development and behaviour of mice. They showed a low survival rate and a big devaluation in the activation of intracellular signaling pathways associated with Akt, S6, ERK1/2 and eEF2 during development, as well as serious behavioural disorders. It was suggested that Shank1 and Shank3 proteins are essential for developmental adjustment of Akt activation and other intracellular pathways that are critical for mammalian postnatal brain development and synaptic plasticity. It is important to note that a full description of the complex role of the PI3K/AKT/mTOR pathways in brain development is beyond the scope of this review. Nevertheless, the diversity of binding partners is being expanded, as a recent study has discovered new components of mammalian targets of rapamycin (mTOR) signaling pathways in neurodevelopment [94]. In this context, another scaffolding protein which is present in high concentrations in the PSD of neurons located in various brain areas is the Insulin receptor substrate p53 (IRSp53, also known as BAIAP2) [95]. IRSp53 directly interacts with PSD95, SHANK proteins and small GTPases like "Cell division control protein 42 homolog” - Cdc42 [96]. Activation of the Rac/Cdc42 cascade regulates actin filaments polymerization in neuronal dendritic spines [97]. Therefore, IRSp53 belongs to crucial elements linked to the Akt pathway that participates in recruiting cytoskeletal elements and synaptic scaffolds, including PSD-95 and SHANK proteins [96]. Studies have shown that IRSp53 is involved in various brain disorders, including ASD $[98,99]$, attention deficit hyperactivity disorder [100] and schizophrenia [101]. A deletion of Irsp53 leads to sexdependent changes in behaviour, such as social deficit, hyperreactivity and excitatory/inhibitory imbalance [102]. A lack of IRSp53 activity leads to NMDA receptor hyperreactivity in the hippocampus [103] and prepulse inhibition in cortical excitatory neurons [102]. The suppression of the mGluR5 and NMDA receptors resulted in improvement of the social deficit in the Irsp53 mutant mice [104].

Knockout mice for the Shank2 gene also display ASDlike behaviour, including reduced social interaction, reduced social communication through ultrasound vocalizations, repeated jumping and also showed a significant decrease in function of the NMDA ( $N$-methyl- ${ }^{-}$-aspartate) glutamate receptor (NMDAR) [105]. Conditional Shank2 deficient mice with deletion in excitatory and inhibitory neurons were used in a study by Kim et al. [106]. Significant changes in synaptic transmission in the hippocampus and striatum were demonstrated, which are associated with different behavioural abnormalities in the social, recurrent, locomotor and anxiety domains. Lee et al. [107] found that Shank2 is expressed in GABAergic neurons, including parvalbumin (PV)-positive neurons, which is a neuronal cell type involved in brain excitation and rhythms, as well as brain dysfunctions, including ASD. A novel Shank2 transcriptional variant in a Shank2 deficient mouse model of ASD has shown that two lines of Shank2 knockout mice generated by deleting different exons (exon 6-7 or exon 7) showed distinct cellular phenotypes. Lee et al. [7] also found expression of a novel exon (exon 4 ' or e4') between the existing exons 4 and 5 in the Shank2 model of e6-7 Shank2 knockout mice. The results suggested an example of genetic indemnity, leading to phenotypic heterogeneity among ASD patients with the same gene mutation. The causative contribution of rare point SHANK2 gene mutations in schizophrenia has also been suggested [108]. Furthermore, new transcriptional variants can work as modifier genes, thereby contributing to differences between two SHANK2 lines of mutation. Bey et al. [109] investigated determined preliminary behaviour in Shank3-knockout mice in striatal inhibitory neurons and self-grooming lesions were noticed in excitatory neurons of the forebrain. In contrast, social, communicative and instrumental learning behaviours were not significantly affected in these mice. Unique patterns of changes in biochemical and electrophysiological findings 


\section{Glutamatergic synapse}

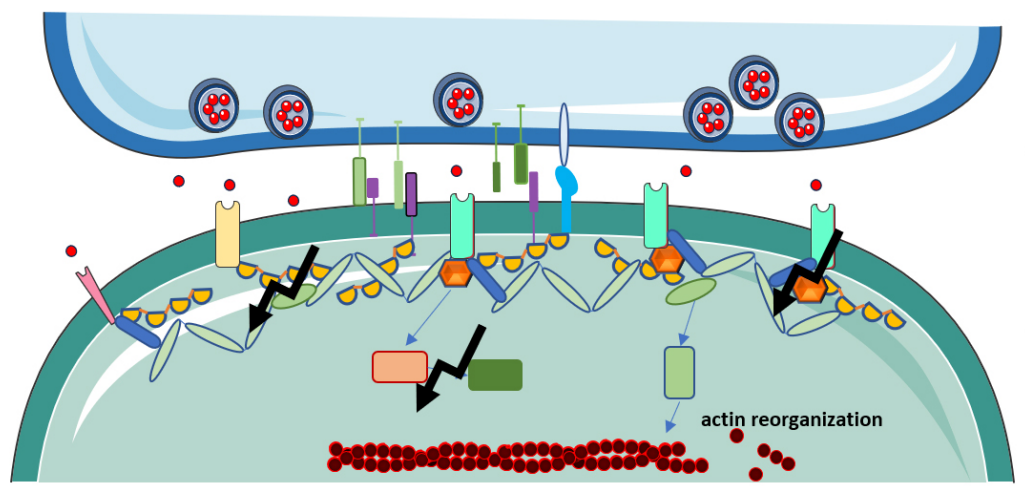

Autism-related conditions

Altered interactions of scaffolding proteins

Complex changes in synaptic neurotransmition

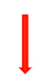

Abnormal behavioural phenotype

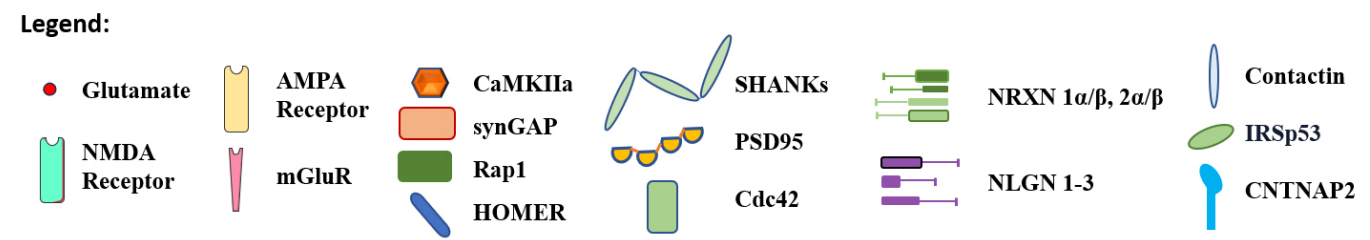

Fig. 1. Schematic representation of glutamatergic synapse, showing altered interactions (thunderbolt sign) of scaffolding proteins at the postsynaptic density observed in autism-like animal models. $\alpha$-amino-3-hydroxy-5-methyl-4-isoxazolepropionic acid receptor (AMPA) receptor, Calmodulin-dependent protein kinase II-alpha (CaMKII $\alpha$ ), Cell division control protein 42 (Cdc42), contactin-associated protein-like 2 (CNTNAP2), Insulin receptor substrate p53 (IRSp53), $N$-methyl-D-aspartate receptor (NMDA) receptor, metabotropic glutamate receptor 1 and 5 (mGluR), Postsynaptic density protein 95 (PSD-95), Neurexins (NRXNs), Neuroligins (NLGNs), synaptic Ras GTPase-activating protein (synGAP), Ras-proximate-1 or Ras-related protein 1 (Rap1), SH3 domain and ankyrin repeat containing proteins (SHANKs).

in the relevant brain regions have been discovered, which reflects the complex nature of Shank3 transcriptional regulation. Decreased HOMER1b/c and hyper-excitability of the membrane were observed with striatal loss of SHANK3. In comparison, the Shank3 deletion in hippocampal neurons led to an increase in NMDA receptor mediated excitatory current [109]. In individuals with autism spectrum disorders, hyperreactivity with sensory input is a common feature. In a study by Chen et al. [110], both male and female Shank3-deficient mice were more sensitive to relatively weak tactile stimulation. Spontaneous and stimulus-induced calcium jets in pyramidal neurons were detected in population-based calcium imaging of the population; however, activity in interneurons was reduced. Preferential deletion of Shank3 in inhibitory interneurons indicated pyramidal neuron hyperactivity. This study suggests that cortical GABAergic interneuron dysfunction plays a key role in sensory hyper-reactivity in the Shank3 mouse model of ASD and identifies a potential cellular target for the exploration of therapeutic interventions.

\section{Future perspectives}

It is clear that pathological changes in synapse formation, plasticity and development are caused by altered trafficking and assembly of postsynaptic scaffolding proteins, in- cluding MAGUKs, SHANK proteins and HOMERs (Fig. 1). Although beyond the main scope of this review, it is essential to mention that alterations in presynaptic scaffolding proteins also play a role in synaptic abnormalities observed in autism-related conditions. Recent studies have investigated a role of several components of the presynaptic active zone such as liprin- $\alpha$, glutamine/leucine/lysine/serine-rich protein (ELKS), Rab3a-interacting molecule (RIM), RIMbinding protein (RIM-BP), Bassoon/Piccolo and Munc13 in a neurotransmitter release [111-113]. For example, in a study by Liang et al. [113], it was shown that liprin- $\alpha 2$ determines distribution of presynaptic proteins in an active zone; therefore it is critical for presynaptic vesicular release. Defects in presynaptic protein distribution and alterations in a whole spectrum of cell-adhesion molecules, including liprins and neurexins, are associated with the etiology of neurodevelopmental disorders such as autism [3].

Postsynaptic protein complexes dynamically interact with CaMKII $\alpha$ assuring synaptic plasticity, which is altered under the conditions of autism. Transcriptome analysis of Shank3-overexpression has revealed modification of postsynaptic membrane-related genes in mice [114]. The most recent results indicate that Shank3 deficiency is accompanied by alterations in synaptic proteins in the hippocampus that could 
be reversed by oxytocin treatment [4]. These findings thus open an avenue for further use of Shank3-deficient mice in examining potential treatment strategies. Indeed, other behavioural and pathological consequences in different autismassociated models could be reversed by manipulation with the oxytocin signaling [115]. ASD patients bearing SHANK13 mutations may also benefit from the knowledge gathered from autism-related mouse models that provide information on how different mutations and genetic variants influence the behavioural phenotypes $[2,91]$. A comparison of molecular, neuronal and behavioural abnormalities found in animal models of FXS and models of ASD represented by manipulations with Cntnap2 and Magel2 genes are essential in distinguishing and understanding the risk for the development of neuropsychiatric disorders.

The comprehensive analysis of neuronal subtypes via single-cell sequencing in autism-related mouse models should elucidate relevant data on molecular therapeutic targets. Chen et al. [116] revealed clusters of glutamatergic and GABAergic neuronal subtypes based on their differential expression; however, nothing is known of their developmental patterns in the context of autism spectrum disorders. Therefore, studying early developmental stages of autism-relevant animal models will help the understanding of the origin and development of autistic symptomatology. Specific molecular targets of postsynaptic proteins affected in ASD at different developmental stages may help development of new therapeutic approaches. Association of concrete alterations in postsynaptic scaffolding proteins, as well as their interactions with binding synaptic partners in conjunction with evaluation of behavioural symptoms, represents a valuable approach for elucidating the role of concrete autism relevant dysfunctions of synapses.

\section{Abbreviations}

3' UTR, 3' untranslated region; Akt, protein kinase B; AMPA receptor, $\alpha$-amino-3-hydroxy-5-methyl-4isoxazolepropionic acid receptor; ASD, autism spectrum disorder; BAIAP2, brain-specific angiogenesis inhibitor 1-associated protein 2; CA1, cornu ammonis 1; CaMK, calcium/calmodulin independent kinase; CaMKII $\alpha$, calmodulin-dependent protein kinase II-alpha; Cask, calcium/calmodulin dependent serine protein kinase; Cdc42, cell division control protein 42; CINAP, cask-interacting nucleosome assembly protein; CNTNAP2, contactinassociated protein-like 2; DLG1, discs large homolog; eEF2, eukaryotic elongation factor 2 protein; ELKS, glutamine/leucine/lysine/serine-rich protein; ERK1/2, extracellular signal-regulated kinases; Fmr1, fragile X mental retardation 1; FMRP, fragile $\mathrm{X}$ mental retardation protein; FOXP2, forkhead box P2; FXS, fragile x syndrome; GABA, gamma-aminobutyric acid; GAP, gtpase-activating protein; GKAP, guanylate kinase-associated proteins; GluN2B, NMDA receptor subunit 2B; GRIN2B, glutamate receptor subunit; GuK, guanylate kinase; IL7R, interleukin 7 receptor; IRSp53, insulin receptor substrate p53; LIN-2,7 (L27), protein LIN-2; MAGEL2, mage family member L2; MAGUKs, membrane-associated guanylate kinases; mGlu, metabotropic glutamate; mGluR1, type I metabotropic glutamate receptor; mGluR5, type V metabotropic glutamate receptor; miRNAs, micro ribonucleic acids; mRNA, messenger ribonucleic acid; mTOR, mammalian target

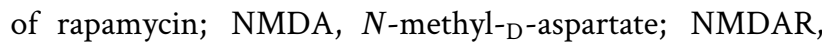
$N$-methyl- ${ }_{D}$-aspartate glutamate receptor; $\mathrm{Nr} 2 \mathrm{~b}, \mathrm{NMDA}$ receptor $2 \mathrm{~b}$; PAR3, partitioning-defective 3 protein; PDZ, post-synaptic density protein 95 - drosophila disc large tumor suppressor - zona occludens 1 domain; PI3K, phosphoinositide 3-kinase; PMS, phelan-mcdermid syndrome; PRD, proline-rich region; PSD, postsynaptic density; PV, parvalbumin; PV+, parvalbumin-expressing; Rac, Ras-related C3 botulinum toxin substrate protein; Rap1, ras-related protein 1; Ras, rat sarcoma virus protein; RIM, rab3a-interacting molecule; RIM-BP, rim-binding protein; RNA, ribonucleic acid; S6, ribosomal protein S6; SAM, sterile alpha motif domain; SAP, synapse-associated protein; SAP, synapseassociated proteins; SAPAP, synapse-associated protein (SAP) 90/postsynaptic density (PSD)-95-associated protein family; SHANK3, SH3 domain and ankyrin repeat containing protein 3; synGAP, ras gtpase-activating proteins; Tbr1, t-box brain transcription factor 1; TSPYL2, testis specific protein y-encoded like 2 .

\section{Author contributions}

VM, JB designed the research study, VM, TH performed the research, VM, TH, ZB, JB wrote the manuscript. All authors contributed to editorial changes in the manuscript. All authors read and approved the final manuscript.

\section{Ethics approval and consent to participate}

Not applicable.

\section{Acknowledgment}

We would like to thank Michael Sabo for proofreading of the manuscript and anonymous reviewers for excellent criticism of the article.

\section{Funding}

The review is based on the work supported by the Grant Agency of the Ministry of Education and the Slovak Academy of Sciences (VEGA 2/0148/21, VEGA 2/0155/20).

\section{Conflict of interest}

The authors declare no conflict of interest.

\section{References}

[1] Bakos J, Bacova Z, Grant SG, Castejon AM, Ostatnikova D. Are Molecules Involved in Neuritogenesis and Axon Guidance Related to Autism Pathogenesis? NeuroMolecular Medicine. 2015; 17: 297-304.

[2] Wang X, Bey AL, Chung L, Krystal AD, Jiang Y. Therapeutic ap- 
proaches for shankopathies. Developmental Neurobiology. 2014; 74: $123-135$.

[3] Guang S, Pang N, Deng X, Yang L, He F, Wu L, et al. Synaptopathology Involved in Autism Spectrum Disorder. Frontiers in Cellular Neuroscience. 2018; 12: 470.

[4] Reichova A, Bacova Z, Bukatova S, Kokavcova M, Meliskova $\mathrm{V}$, Frimmel $\mathrm{K}$, et al. Abnormal neuronal morphology and altered synaptic proteins are restored by oxytocin in autism-related SHANK3 deficient model. Molecular and Cellular Endocrinology. 2020; 518: 110924.

[5] Reichova A, Schaller F, Bukatova S, Bacova Z, Muscatelli F, Bakos $\mathrm{J}$. The impact of oxytocin on neurite outgrowth and synaptic proteins in Magel2-deficient mice. Developmental Neurobiology. 2021; 81: 366-388.

[6] Jaramillo TC, Xuan Z, Reimers JM, Escamilla CO, Liu S, Powell CM. Early Restoration of Shank3 Expression in Shank3 Knock-out Mice Prevents Core ASD-Like Behavioral Phenotypes. Eneuro. 2020; 7: ENEURO.0332-19.2020.

[7] Lee Y, Yu N, Chun J, Yang J, Lim C, Kim H, et al. Identification of a novel Shank2 transcriptional variant in Shank2 knockout mouse model of autism spectrum disorder. Molecular Brain. 2020; 13: 54.

[8] Stephenson JR, Wang X, Perfitt TL, Parrish WP, Shonesy BC, Marks CR, et al. A Novel Human CAMK2A Mutation Disrupts Dendritic Morphology and Synaptic Transmission, and Causes ASD-Related Behaviors. The Journal of Neuroscience. 2017; 37: 2216-2233.

[9] Burket JA, Deutsch SI. Metabotropic functions of the NMDA receptor and an evolving rationale for exploring NR2a-selective positive allosteric modulators for the treatment of autism spectrum disorder. Progress in Neuro-Psychopharmacology \& Biological Psychiatry. 2019; 90: 142-160.

[10] Kaizuka T, Takumi T. Postsynaptic density proteins and their involvement in neurodevelopmental disorders. The Journal of Biochemistry. 2018; 163: 447-455.

[11] Pizzarelli R, Cherubini E. Alterations of GABAergic signaling in autism spectrum disorders. Neural Plasticity. 2011; 2011: 297153.

[12] Allison DW, Chervin AS, Gelfand VI, Craig AM. Postsynaptic scaffolds of excitatory and inhibitory synapses in hippocampal neurons: maintenance of core components independent of actin filaments and microtubules. The Journal of Neuroscience. 2000; 20: 4545-4554.

[13] Sheng M, Kim E. The postsynaptic organization of synapses. Cold Spring Harbor Perspectives in Biology. 2011; 3: a005678.

[14] Grant SGN. Synapse diversity and synaptome architecture in human genetic disorders. Human Molecular Genetics. 2019; 28: R219-R225.

[15] Xing X, Zhang J, Wu K, Cao B, Li X, Jiang F, et al. Suppression of Akt-mTOR pathway rescued the social behavior in Cntnap2deficient mice. Scientific Reports. 2019; 9: 3041.

[16] Jurgensen S, Castillo PE. Selective Dysregulation of Hippocampal Inhibition in the Mouse Lacking Autism Candidate Gene CNTNAP2. The Journal of Neuroscience. 2015; 35: 14681-14687.

[17] Lu Z, Reddy MVVVS, Liu J, Kalichava A, Liu J, Zhang L, et al. Molecular Architecture of Contactin-associated Protein-like 2 (CNTNAP2) and its Interaction with Contactin 2 (CNTN2). The Journal of Biological Chemistry. 2016; 291: 24133-24147.

[18] Kennedy MB. The postsynaptic density at glutamatergic synapses. Trends in Neurosciences. 1997; 20: 264-268.

[19] Kornau H, Schenker L, Kennedy M, Seeburg P. Domain interaction between NMDA receptor subunits and the postsynaptic density protein PSD-95. Science. 1995; 269: 1737-1740.

[20] Coley AA, Gao W. PSD95: a synaptic protein implicated in schizophrenia or autism? Progress in NeuroPsychopharmacology \& Biological Psychiatry. 2018; 82: 187-194.

[21] Verpelli C, Schmeisser MJ, Sala C, Boeckers TM. Scaffold proteins at the postsynaptic density. Advances in Experimental Medicine and Biology. 2012; 970: 29-61.

[22] Funke L, Dakoji S, Bredt DS. Membrane-associated guanylate kinases regulate adhesion and plasticity at cell junctions. Annual Review of Biochemistry. 2005; 74: 219-245.
[23] Zheng C, Petralia RS, Wang Y, Kachar B, Wenthold RJ. SAP102 is a highly mobile MAGUK in spines. The Journal of Neuroscience. 2010; 30: 4757-4766.

[24] Gardoni F. MAGUK proteins: new targets for pharmacological intervention in the glutamatergic synapse. European Journal of Pharmacology. 2008; 585: 147-152.

[25] Liu S, Zhou L, Yuan H, Vieira M, Sanz-Clemente A, Badger JD, et al. A Rare Variant Identified within the GluN2B C-Terminus in a Patient with Autism Affects NMDA Receptor Surface Expression and Spine Density. The Journal of Neuroscience. 2017; 37: 4093 4102.

[26] McEachern EP, Coley AA, Yang S, Gao W. PSD-95 deficiency alters GABAergic inhibition in the prefrontal cortex. Neuropharmacology. 2020; 179: 108277.

[27] Moutin E, Raynaud F, Fagni L, Perroy J. GKAP-DLC2 interaction organizes the postsynaptic scaffold complex to enhance synaptic NMDA receptor activity. Journal of Cell Science. 2012; 125: 2030 2040.

[28] Kreienkamp H. Scaffolding proteins at the postsynaptic density: shank as the architectural framework. Handbook of Experimental Pharmacology. 2008; 365-380.

[29] Grabrucker AM, Schmeisser MJ, Schoen M, Boeckers TM. Postsynaptic ProSAP/Shank scaffolds in the cross-hair of synaptopathies. Trends in Cell Biology. 2011; 21: 594-603.

[30] Qiu S, Li Y, Bai Y, Shi J, Cui H, Gu Y, et al. SHANK1 polymorphisms and SNP-SNP interactions among SHANK family: A possible cue for recognition to autism spectrum disorder in infant age. Autism Research. 2019; 12: 375-383.

[31] Ha HTT, Leal-Ortiz S, Lalwani K, Kiyonaka S, Hamachi I, Mysore SP, et al. Shank and Zinc Mediate an AMPA Receptor Subunit Switch in Developing Neurons. Frontiers in Molecular Neuroscience. 2018; 11: 405.

[32] Collins SM, Belagodu AP, Reed SL, Galvez R. SHANK1 is differentially expressed during development in CA1 hippocampal neurons and astrocytes. Developmental Neurobiology. 2018; 78: 363373.

[33] Lee S, Kim JA, Chang S. NArgBP2-SAPAP-SHANK, the core postsynaptic triad associated with psychiatric disorders. Experimental \& Molecular Medicine. 2018; 50: 1-9.

[34] Monteiro P, Feng G. SHANK proteins: roles at the synapse and in autism spectrum disorder. Nature Reviews Neuroscience. 2017; 18: $147-157$.

[35] Amal H, Barak B, Bhat V, Gong G, Joughin BA, Wang X, et al. Shank3 mutation in a mouse model of autism leads to changes in the S-nitroso-proteome and affects key proteins involved in vesicle release and synaptic function. Molecular Psychiatry. 2020; 25: 1835-1848.

[36] Tao-Cheng J, Yang Y, Bayer KU, Reese TS, Dosemeci A. NMDAinduced accumulation of Shank at the postsynaptic density is mediated by CaMKII. Biochemical and Biophysical Research Communications. 2014; 450: 808-811.

[37] Hayashi MK, Tang C, Verpelli C, Narayanan R, Stearns MH, Xu R, et al. The Postsynaptic Density Proteins Homer and Shank Form a Polymeric Network Structure. Cell. 2009; 137: 159-171.

[38] Heavner WE, Lautz JD, Speed HE, Gniffke EP, Immendorf $\mathrm{KB}$, Welsh JP, et al. Remodeling of the Homer-Shank interactome mediates homeostatic plasticity. Science Signaling. 2021; 14: eabd7325.

[39] Soler J, Fañanás L, Parellada M, Krebs M, Rouleau GA, FatjóVilas M. Genetic variability in scaffolding proteins and risk for schizophrenia and autism-spectrum disorders: a systematic review. Journal of Psychiatry \& Neuroscience. 2018; 43: 223-244.

[40] Tu JC, Xiao B, Naisbitt S, Yuan JP, Petralia RS, Brakeman P, et al. Coupling of mGluR/Homer and PSD-95 complexes by the Shank family of postsynaptic density proteins. Neuron. 1999; 23: $583-$ 592.

[41] D’Antoni S, Spatuzza M, Bonaccorso CM, Musumeci SA, Ciranna L, Nicoletti F, et al. Dysregulation of group-i metabotropic glutamate (mGlu) receptor mediated signalling in disorders associated with Intellectual Disability and Autism. Neuroscience and Biobe- 
havioral Reviews. 2014; 46: 228-241.

[42] Walkup WG, Mastro TL, Schenker LT, Vielmetter J, Hu R, Iancu A, et al. A model for regulation by SynGAP- $\alpha 1$ of binding of synaptic proteins to PDZ-domain 'Slots' in the postsynaptic density. Elife. 2017; 5: e16813.

[43] Cornelia Koeberle S, Tanaka S, Kuriu T, Iwasaki H, Koeberle A Schulz A, et al. Developmental stage-dependent regulation of spine formation by calcium-calmodulin-dependent protein kinase II $\alpha$ and Rap1. Scientific Reports. 2017; 7: 13409.

[44] Cai Q, Zeng M, Wu X, Wu H, Zhan Y, Tian R, et al. CaMKII $\alpha$ driven, phosphatase-checked postsynaptic plasticity via phase separation. Cell Research. 2021; 31: 37-51.

[45] Perfitt TL, Stauffer PE, Spiess KL, Colbran RJ. CaMKII $\alpha$ phosphorylation of Shank3 modulates ABI1-Shank3 interaction. Biochemical and Biophysical Research Communications. 2020; 524: 262-267.

[46] Falougy HE, Filova B, Ostatnikova D, Bacova Z, Bakos J. Neuronal morphology alterations in autism and possible role of oxytocin. Endocrine Regulations. 2019; 53: 46-54.

[47] Premoli M, Memo M, Bonini S. Ultrasonic vocalizations in mice: relevance for ethologic and neurodevelopmental disorders studies. Neural Regeneration Research. 2021; 16: 1158.

[48] Peleh T, Eltokhi A, Pitzer C. Longitudinal analysis of ultrasonic vocalizations in mice from infancy to adolescence: Insights into the vocal repertoire of three wild-type strains in two different social contexts. PLoS ONE. 2019; 14: e0220238.

[49] de la Torre-Ubieta L, Won H, Stein JL, Geschwind DH. Advancing the understanding of autism disease mechanisms through genetics. Nature Medicine. 2016; 22: 345-361.

[50] Fazel Darbandi S, Robinson Schwartz SE, Pai EL, Everitt A, Turner ML, Cheyette BNR, et al. Enhancing WNT Signaling Restores Cortical Neuronal Spine Maturation and Synaptogenesis in Tbr1 Mutants. Cell Reports. 2020; 31: 107495

[51] Yook C, Kim K, Kim D, Kang H, Kim S, Kim E, et al. A TBR1K228E Mutation Induces Tbr1 Upregulation, Altered Cortical Distribution of Interneurons, Increased Inhibitory Synaptic Transmission, and Autistic-Like Behavioral Deficits in Mice. Frontiers in Molecular Neuroscience. 2019; 12: 241

[52] Liu J, Reggiani JDS, Laboulaye MA, Pandey S, Chen B, Rubenstein JLR, et al. Tbr1 instructs laminar patterning of retinal ganglion cell dendrites. Nature Neuroscience. 2018; 21: 659-670.

[53] Elsen GE, Bedogni F, Hodge RD, Bammler TK, MacDonald JW, Lindtner S, et al. The Epigenetic Factor Landscape of Developing Neocortex is Regulated by Transcription Factors Pax6 $\rightarrow$ Tbr2 $\rightarrow$ Tbr1. Frontiers in Neuroscience. 2018; 12: 571.

[54] Marinaro F, Marzi MJ, Hoffmann N, Amin H, Pelizzoli R, Niola $\mathrm{F}$, et al. MicroRNA-independent functions of DGCR8 are essential for neocortical development and TBR1 expression. EMBO Reports. 2017; 18: 603-618.

[55] LaConte LEW, Chavan V, Elias AF, Hudson C, Schwanke C, Styren $\mathrm{K}$, et al. Two microcephaly-associated novel missense mutations in CASK specifically disrupt the CASK-neurexin interaction. Human Genetics. 2018; 137: 231-246.

[56] Wang G, Hong C, Yen T, Huang H, Ou Y, Huang T, et al. Transcriptional modification by a CASK-interacting nucleosome assembly protein. Neuron. 2004; 42: 113-128.

[57] Deriziotis P, O’Roak BJ, Graham SA, Estruch SB, Dimitropoulou $\mathrm{D}$, Bernier RA, et al. De novo TBR1 mutations in sporadic autism disrupt protein functions. Nature Communications. 2014; 5: 4954

[58] Sakai Y, Shaw CA, Dawson BC, Dugas DV, Al-Mohtaseb Z, Hill $\mathrm{DE}$, et al. Protein interactome reveals converging molecular pathways among autism disorders. Science Translational Medicine. 2011; 3: 86ra49.

[59] Huang T, Hsueh Y. Brain-specific transcriptional regulator Tbrain-1 controls brain wiring and neuronal activity in autism spectrum disorders. Frontiers in Neuroscience. 2015; 9: 406.

[60] Srivastava S, McMillan R, Willis J, Clark H, Chavan V, Liang C, et al. X-linked intellectual disability gene $C A S K$ regulates postnatal brain growth in a non-cell autonomous manner. Acta Neuropathologica Communications. 2016; 4: 30.

[61] Liang C, Kerr A, Qiu Y, Cristofoli F, Van Esch H, Fox MA, et al.
Optic Nerve Hypoplasia is a Pervasive Subcortical Pathology of Visual System in Neonates. Investigative Ophthalmology \& Visual Science. 2017; 58: 5485-5496.

[62] den Hoed J, Sollis E, Venselaar H, Estruch SB, Deriziotis P, Fisher SE. Functional characterization of TBR1 variants in neurodevelopmental disorder. Scientific Reports. 2018; 8: 14279.

[63] Huang T, Yen T, Qiu LR, Chuang H, Lerch JP, Hsueh Y. Haploinsufficiency of autism causative gene Tbr1 impairs olfactory discrimination and neuronal activation of the olfactory system in mice. Molecular Autism. 2019; 10: 5.

[64] Sitzmann AF, Hagelstrom RT, Tassone F, Hagerman RJ, Butler MG. Rare FMR1 gene mutations causing fragile $\mathrm{X}$ syndrome: a review. American Journal of Medical Genetics: Part A. 2018; 176: 11-18.

[65] Hagerman RJ, Berry-Kravis E, Hazlett HC, Bailey DB, Moine H, Kooy RF, et al. Fragile X syndrome. Nature Reviews. Disease Primers. 2017; 3: 17065.

[66] Ishii K, Nagaoka A, Kishida Y, Okazaki H, Yagishita S, Ucar H, et al. In Vivo Volume Dynamics of Dendritic Spines in the Neocortex of Wild-Type and Fmr1 KO Mice. ENeuro. 2018; 5: ENEURO.028218.2018.

[67] Davis JK, Broadie K. Multifarious Functions of the Fragile X Mental Retardation Protein. Trends in Genetics. 2017; 33: 703-714.

[68] Qin M, Kang J, Smith CB. Increased rates of cerebral glucose metabolism in a mouse model of fragile $\mathrm{X}$ mental retardation. Proceedings of the National Academy of Sciences of the United States of America. 2002; 99: 15758-15763.

[69] Davidovic L, Navratil V, Bonaccorso CM, Catania MV, Bardoni B, Dumas M. A metabolomic and systems biology perspective on the brain of the fragile X syndrome mouse model. Genome Research. 2011; 21: 2190-2202.

[70] Todd PK, Mack KJ, Malter JS. The fragile X mental retardation protein is required for type-i metabotropic glutamate receptordependent translation of PSD-95. Proceedings of the National Academy of Sciences of the United States of America. 2003; 100: 14374-14378.

[71] Westmark CJ, Malter JS. FMRP mediates mGluR5-dependent translation of amyloid precursor protein. PLoS Biology. 2007; 5: e52.

[72] DeMarco B, Stefanovic S, Williams A, Moss KR, Anderson BR, Bassell GJ, et al. FMRP - G-quadruplex mRNA - miR-125a interactions: Implications for miR-125a mediated translation regulation of PSD-95 mRNA. PLoS ONE. 2019; 14: e0217275.

[73] Sabanov V, Braat S, D'Andrea L, Willemsen R, Zeidler S, Rooms $\mathrm{L}$, et al. Impaired GABAergic inhibition in the hippocampus of Fmr1 knockout mice. Neuropharmacology. 2017; 116: 71-81.

[74] Saint-Martin M, Joubert B, Pellier-Monnin V, Pascual O, Noraz N, Honnorat J. Contactin-associated protein-like 2, a protein of the neurexin family involved in several human diseases. European Journal of Neuroscience. 2018; 48: 1906-1923.

[75] Vogt D, Cho KKA, Shelton SM, Paul A, Huang ZJ, Sohal VS, et al. Mouse Cntnap2 and Human CNTNAP2 ASD Alleles Cell Autonomously Regulate PV+ Cortical Interneurons. Cerebral Cortex. 2018 ; 28: 3868-3879.

76] Lazaro MT, Taxidis J, Shuman T, Bachmutsky I, Ikrar T, Santos R, et al. Reduced Prefrontal Synaptic Connectivity and Disturbed Oscillatory Population Dynamics in the CNTNAP2 Model of Autism. Cell Reports. 2019; 27: 2567-2578.e6.

77] Scott KE, Kazazian K, Mann RS, Möhrle D, Schormans AL, Schmid S, et al. Loss of Cntnap2 in the Rat Causes Autism-Related Alterations in Social Interactions, Stereotypic Behavior, and Sensory Processing. Autism Research. 2020; 13: 1698-1717.

[78] Gao R, Pratt CP, Yoon S, Martin-de-Saavedra MD, Forrest MP, Penzes P. CNTNAP2 is targeted to endosomes by the polarity protein PAR3. European Journal of Neuroscience. 2020; 51: 1074 1086.

[79] Varea O, Martin-de-Saavedra MD, Kopeikina KJ, Schürmann B, Fleming HJ, Fawcett-Patel JM, et al. Synaptic abnormalities and cytoplasmic glutamate receptor aggregates in contactin associated protein-like 2/Caspr2 knockout neurons. Proceedings of the $\mathrm{Na}-$ 
tional Academy of Sciences of the United States of America. 2015; 112: 6176-6181.

[80] Sacai H, Sakoori K, Konno K, Nagahama K, Suzuki H, Watanabe $\mathrm{T}$, et al. Autism spectrum disorder-like behavior caused by reduced excitatory synaptic transmission in pyramidal neurons of mouse prefrontal cortex. Nature Communications. 2020; 11: 5140.

[81] Tacer KF, Potts PR. Cellular and disease functions of the PraderWilli Syndrome gene MAGEL2. Biochemical Journal. 2017; 474: 2177-2190.

[82] Carias KV, Zoeteman M, Seewald A, Sanderson MR, Bischof JM, Wevrick R. A MAGEL2-deubiquitinase complex modulates the ubiquitination of circadian rhythm protein CRY1. PLoS ONE. 2020; 15: e0230874.

[83] Srancikova A, Bacova Z, Bakos J. The epigenetic regulation of synaptic genes contributes to the etiology of autism. Reviews in the Neurosciences. 2021; 32: 791-802.

[84] Schaller F, Watrin F, Sturny R, Massacrier A, Szepetowski P, Muscatelli F. A single postnatal injection of oxytocin rescues the lethal feeding behaviour in mouse newborns deficient for the imprinted Magel2 gene. Human Molecular Genetics. 2010; 19: 48954905.

[85] Meziane H, Schaller F, Bauer S, Villard C, Matarazzo V, Riet F, et al. An Early Postnatal Oxytocin Treatment Prevents Social and Learning Deficits in Adult Mice Deficient for Magel2, a Gene Involved in Prader-Willi Syndrome and Autism. Biological Psychiatry. 2015; 78: 85-94.

[86] Mossa A, Pagano J, Ponzoni L, Tozzi A, Vezzoli E, Sciaccaluga M, et al. Developmental impaired Akt signaling in the Shank1 and Shank3 double knock-out mice. Molecular Psychiatry. 2021; 26: 1928-1944.

[87] YooJ, Bakes J, Bradley C, Collingridge GL, Kaang B. Shank mutant mice as an animal model of autism. Philosophical Transactions of the Royal Society of London. Series B, Biological Sciences. 2013; 369: 20130143.

[88] Wang X, McCoy PA, Rodriguiz RM, Pan Y, Je HS, Roberts AC, et al. Synaptic dysfunction and abnormal behaviors in mice lacking major isoforms of Shank3. Human Molecular Genetics. 2011; 20: 3093-3108.

[89] Gong X, Wang H. SHANK1 and autism spectrum disorders. Science China Life Sciences. 2015; 58: 985-990.

[90] Hung AY, Futai K, Sala C, Valtschanoff JG, Ryu J, Woodworth MA, et al. Smaller dendritic spines, weaker synaptic transmission, but enhanced spatial learning in mice lacking Shank1. The Journal of Neuroscience. 2008; 28: 1697-1708.

[91] Jiang Y, Ehlers MD. Modeling autism by SHANK gene mutations in mice. Neuron. 2013; 78: 8-27.

[92] Sungur AÖ, Jochner MCE, Harb H, Kılıç A, Garn H, Schwarting RKW, et al. Aberrant cognitive phenotypes and altered hippocampal BDNF expression related to epigenetic modifications in mice lacking the post-synaptic scaffolding protein SHANK1: Implications for autism spectrum disorder. Hippocampus. 2017; 27: 906919.

[93] Mao W, Watanabe T, Cho S, Frost JL, Truong T, Zhao X, et al. Shank1 regulates excitatory synaptic transmission in mouse hippocampal parvalbumin-expressing inhibitory interneurons. European Journal of Neuroscience. 2015; 41: 1025-1035.

[94] Kim S, Lee S, Kim Y, Park J, Woo D, Kim D, et al. Tanc2-mediated $\mathrm{mTOR}$ inhibition balances mTORC1/2 signaling in the developing mouse brain and human neurons. Nature Communications. 2021; 12: 2695

[95] Burette AC, Park H, Weinberg RJ. Postsynaptic distribution of IRSp53 in spiny excitatory and inhibitory neurons. Journal of Comparative Neurology. 2014; 522: 2164-2178.

[96] Kang J, Park H, Kim E. IRSp53/BAIAP2 in dendritic spine development, NMDA receptor regulation, and psychiatric disorders. Neuropharmacology. 2016; 100: 27-39.

[97] Choi J, Ko J, Racz B, Burette A, Lee J, Kim S, et al. Regulation of dendritic spine morphogenesis by insulin receptor substrate 53 , a downstream effector of Rac1 and Cdc42 small GTPases. Journal of
Neuroscience. 2005; 25: 869-879.

[98] Celestino-Soper PBS, Shaw CA, Sanders SJ, Li J, Murtha MT, Ercan-Sencicek AG, et al. Use of array CGH to detect exonic copy number variants throughout the genome in autism families detects a novel deletion in TMLHE. Human Molecular Genetics. 2011; 20: 4360-4370.

[99] Levy D, Ronemus M, Yamrom B, Lee Y, Leotta A, Kendall J, et al. Rare de novo and transmitted copy-number variation in autistic spectrum disorders. Neuron. 2011; 70: 886-897.

[100] Liu L, Sun L, Li Z, Li H, Wei L, Wang Y, et al. BAIAP2 exhibits association to childhood ADHD especially predominantly inattentive subtype in Chinese Han subjects. Behavioral and Brain Functions. 2013; 9: 48.

[101] Fromer M, Pocklington AJ, Kavanagh DH, Williams HJ, Dwyer $\mathrm{S}$, Gormley $\mathrm{P}$, et al. De novo mutations in schizophrenia implicate synaptic networks. Nature. 2014; 506: 179-184.

[102] Kim Y, Noh YW, Kim K, Yang E, Kim H, Kim E. IRSp53 Deletion in Glutamatergic and GABAergic Neurons and in Male and Female Mice Leads to Distinct Electrophysiological and Behavioral Phenotypes. Frontiers in Cellular Neuroscience. 2020; 14: 23.

[103] Kim M-, Choi J, Yang J, Chung W, Kim J-, Paik SK, et al. Enhanced NMDA Receptor-Mediated Synaptic Transmission, Enhanced Long-Term Potentiation, and Impaired Learning and Memory in Mice Lacking IRSp53. Journal of Neuroscience. 2009; 29: 1586-1595.

[104] Chung W, Choi SY, Lee E, Park H, Kang J, Park H, et al. Social deficits in IRSp53 mutant mice improved by NMDAR and mGluR5 suppression. Nature Neuroscience. 2015; 18: 435-443.

[105] Won H, Lee H, Gee HY, Mah W, Kim J, Lee J, et al. Autisticlike social behaviour in Shank2-mutant mice improved by restoring NMDA receptor function. Nature. 2012; 486: 261-265.

[106] Kim R, Kim J, Chung C, Ha S, Lee S, Lee E, et al. Cell-TypeSpecific Shank2 Deletion in Mice Leads to Differential Synaptic and Behavioral Phenotypes. Journal of Neuroscience. 2018; 38: 4076-4092.

[107] Lee S, Lee E, Kim R, Kim J, Lee S, Park H, et al. Shank2 Deletion in Parvalbumin Neurons Leads to Moderate Hyperactivity, Enhanced Self-Grooming and Suppressed Seizure Susceptibility in Mice. Frontiers in Molecular Neuroscience. 2018; 11: 209.

[108] Peykov S, Berkel S, Schoen M, Weiss K, Degenhardt F, Strohmaier J, et al. Identification and functional characterization of rare SHANK2 variants in schizophrenia. Molecular Psychiatry. 2015; 20: 1489-1498.

[109] Bey AL, Wang X, Yan H, Kim N, Passman RL, Yang Y, et al. Brain region-specific disruption of Shank3 in mice reveals a dissociation for cortical and striatal circuits in autism-related behaviors. Translational Psychiatry. 2018; 8: 94.

[110] Chen Q, Deister CA, Gao X, Guo B, Lynn-Jones T, Chen N, et al. Dysfunction of cortical GABAergic neurons leads to sensory hyper-reactivity in a Shank3 mouse model of ASD. Nature Neuroscience. 2020; 23: 520-532.

[111] Biederer T, Kaeser PS, Blanpied TA. Transcellular Nanoalignment of Synaptic Function. Neuron. 2017; 96: 680-696.

[112] Emperador-Melero J, Kaeser PS. Assembly of the presynaptic active zone. Current Opinion in Neurobiology. 2020; 63: 95-103.

[113] Liang M, Jin G, Xie X, Zhang W, Li K, Niu F, et al. Oligomerized liprin- $\alpha$ promotes phase separation of ELKS for compartmentalization of presynaptic active zone proteins. Cell Reports. 2021; 34: 108901.

[114] Jin C, Kang H, Ryu JR, Kim S, Zhang Y, Lee Y, et al. Integrative Brain Transcriptome Analysis Reveals Region-Specific and Broad Molecular Changes in Shank3-Overexpressing Mice. Frontiers in Molecular Neuroscience. 2018; 11: 250.

[115] Hörnberg H, Pérez-Garci E, Schreiner D, Hatstatt-Burklé L, Magara F, Baudouin $\mathrm{S}$, et al. Rescue of oxytocin response and social behaviour in a mouse model of autism. Nature. 2020; 584: 252256.

[116] Chen R, Wu X, Jiang L, Zhang Y. Single-Cell RNA-Seq Reveals Hypothalamic Cell Diversity. Cell Reports. 2017; 18: 3227-3241. 